\title{
PORTFÓLIO REFLEXIVO: UMA FERRAMENTA NA EDUCAÇÃO PROFISSIONAL
}

\author{
Lúcia Adriana Pereira Jungles ${ }^{1}$ \\ Adriana Magedanz $z^{2}$
}

\begin{abstract}
Resumo: As mudanças que vêm ocorrendo na sociedade e no mercado de trabalho fazem com que as instituiçóes de ensino busquem novas metodologias em sala de aula, revendo seus projetos pedagógicos e estimulando a formaçáo continuada dos seus docentes para a utilização de novos métodos de ensino. Neste estudo pretendeu-se apresentar uma das ferramentas que podem ser utilizadas pelo docente em sala de aula: o portfólio. Enquanto ferramenta de ensino, aprendizagem e avaliação, o portfólio é um trabalho desenvolvido pelos próprios alunos. Ao fazê-lo, os envolvidos se revelam por meio de diferentes linguagens, pois evidenciam não só que "assimilaram" conteúdos, mas sim como vão se constituindo como profissionais. Este estudo é do tipo descritivo exploratório, de abordagem qualitativa e quantitativa, embasado na análise de conteúdo, de onde emergiram sete categorias. A pesquisa foi desenvolvida na disciplina de Saúde Coletiva, foi realizada um questionário com os alunos da disciplina, participaram um total de 31 alunos. O portfólio, portanto, constitui um compilado de trabalhos no qual os alunos apresentaram a sua história de vida, seus progressos, suas dificuldades, suas realizaçóes, as escolhas dos conteúdos abordados e discutidos, estimulando a construção de um pensamento crítico-reflexivo.
\end{abstract}

Palavras-chave: Portfólio reflexivo. Metodologias ativas. Aprendizagem. Ensino.

\section{REFLECTIVE PORTFOLIO: A TOOL IN PROFESSIONAL EDUCATION}

\begin{abstract}
The changes that have been taking place in society and in the labor market have made it possible for educational institutions to seek out new methodologies in the classroom, reviewing their pedagogical projects and stimulating the continuous training of their teachers to use new teaching methods. In this study we intend to present one of the tools that can be used by the teacher in
\end{abstract}

1 Bacharel em Enfermagem. Acadêmica do Curso de Pós-graduação em Docência na Educação Profissional. Universidade do Vale do Taquari - UNIVATES. Enfermeira e Professora.

2 Orientadora. Licenciada em Ciências e Matemática. Especialista em Ensino de Matemática. Mestre em Ensino de Ciências Exatas. Doutoranda em Ensino. Universidade do Vale do Taquari - UNIVATES. Professora. 
the classroom: the portfolio. As a teaching, learning and evaluation tool, the portfolio is a work developed by the students themselves. In doing so, those involved are revealed through different languages, as they demonstrate not only that they "assimilated" content, but rather how they are becoming professionals. This is a descriptive, exploratory, qualitative and quantitative approach, based on content analysis, from which seven categories emerged. The research was developed in the discipline of Collective Health, a questionnaire was carried out with the students of the discipline, a total of 31 students participated. The portfolio, therefore, is a compilation of works in which the students presented their life history, their progress, their difficulties, their achievements, the choices of the contents addressed and discussed, stimulating the construction of critical-reflexive thinking.

Keywords: Reflective portfolio. Active methodologies. Learning. Teaching.

\section{CONSIDERAÇÓES INICIAIS}

No decorrer dos séculos, a sociedade vem se modificando cada vez mais e as instituições educacionais não podem se manter alheias, havendo a necessidade dos professores se adaptarem e buscarem novas formas de trabalho em sala de aula. Neste contexto, as metodologias ativas de aprendizagem são entendidas como uma proposta que visa a focar o processo de ensinar e aprender, na busca da participação ativa de todos os envolvidos, centrados na realidade em que estão inseridos, sendo do aluno o agente principal responsável pela sua aprendizagem (WILDNER, 2016).

No contexto histórico, a formação de profissionais de todas as áreas têm utilizado uma metodologia conservadora, na qual se concebe o corpo separado da mente, a razão do sentimento, a ciência da ética. Assim, o processo de ensino e de aprendizagem se restringe a reprodução do conhecimento, onde o docente assume o papel de transmissor de conteúdos e ao aluno cabe a retenção e a repetição dos mesmos, em uma atitude passiva, tornando-se um mero expectador (BEHRENS, 2005).

A partir disso, as novas Diretrizes Curriculares Nacionais - DCN (BRASIL, 2001 ; 2012) dos cursos da área da saúde vêm propondo um processo de mudança no ensino e na aprendizagem, dando protagonismo ao estudante. As mudanças orientam uma formação profissional segundo os princípios do Sistema Único de Saúde (SUS), considerando as necessidades de saúde da população, reorientando o modelo assistencial, trabalhando mais a promoção da saúde e seus determinantes sociais, formando profissionais-cidadãos engajados na luta pela recuperação da dimensão essencial do trabalho em saúde (CYRINO; TORALLES-PEREIRA, 2004; COTTA et al., 2012).

Essa luta dentro do trabalho em saúde, onde se buscam mudanças nos processos de trabalho, pensando mais prevenção e promoção utilizando o conceito ampliado de saúde, exige que os profissionais estejam mais qualificados. Portanto é preciso repensar a formação, os métodos de ensino e buscar novas ferramentas de aprendizagem. Uma das ferramentas que pode ser utilizada é o portfólio. 


\section{PORTFÓLIO: UM POUCO DE TEORIA}

A educação profissional é uma modalidade de ensino que forma profissionais para o trabalho. Formar profissionais por meio das práticas do dia a dia, ou seja, formação voltada às necessidades do mercado de trabalho, limita uma visão mais crítica do seu papel na sociedade (SANTOS et al., 2017).

Essa visão de mercado de trabalho e da educação profissional se distancia muito das discussões realizadas por Moura (2013), Ramos (2015, texto digital) e Ciavatta (2012). Estes autores defendem a ideia de que a formação profissional deve ir além da preparação técnica. Deveria ser uma formação completa, integral e que trabalhasse cultura, tecnologia e ciência. Para que isso ocorra é preciso preparar o aluno para um contexto mais amplo, aproximando ele da sua realidade.

Uma formação que aproxime o aluno à vida real requer o uso de metodologias que despertem a criatividade e o capacitem à resolução de situações problemas, desenvolvendo um pensamento crítico reflexivo. Para que essas mudanças ocorram é preciso uma renovação na docência, com transformações de conceitos que transcendem o ensino tradicional e integrem às práticas pedagógicas novos instrumentos, que permitam ao aluno alcançar competências para o exercício profissional.

Essas mudanças na educação são consideradas um desafio, pois é preciso buscar metodologias que ultrapassem o limite do treinamento ou da capacitação técnica tradicional, para a formação de um sujeito reflexivo, crítico, transformador e humanizado. Isso é um grande desafio para o docente, pois exige uma mudança na forma de planejar as aulas. O uso das metodologias ativas é uma maneira de buscar a autonomia do aluno, tanto em nível pessoal quanto social, o aluno se torna o centro do seu aprendizado (GASTARDELLI, 2016).

Contudo, as metodologias ativas que buscam a autonomia do aluno compartilham uma preocupação. Paiva (2017, p.146) destaca que:

As metodologias ativas de ensino-aprendizagem compartilham uma preocupação, porém, não se pode afirmar que são uniformes tanto do ponto de vista dos pressupostos teóricos como metodológicos; assim, identificamse diferentes modelos e estratégias para sua operacionalização, constituindo alternativas para o processo de ensino aprendizagem, com diversos benefícios e desafios, nos diferentes níveis educacionais.

Entre as diferentes estratégias, Anastasiou e Alves (2005, p. 81 e 82), propõem várias ferramentas para serem utilizadas em sala de aula, que possibilitam o acompanhamento da construção do conhecimento. Um dos instrumentos propostos pelas autoras é o portfólio.

O portfólio exige do professor um alto grau de organização, no sentido de acompanhar as produções/manifestações escritas dos estudantes. Dentre as inúmeras atividades que a prática pedagógica coloca à disposição para a sala de aula, o portfólio se apresenta como o mais completo: propicia ao professor verificar de forma imediata as dificuldades apresentadas pelo estudante e propor soluções para sua superação. É um processo individual que permite 
a cada um crescer de acordo com suas necessidades e condições. Pode ser estabelecida com diferentes objetivos, devendo a avaliação se referir a eles. Utilizada como mobilização. Desperta nos estudantes rápida vinculação como objeto de estudo; pode ser utilizada no sentido de coletar sugestões para resolver um problema do contexto durante o processo de construção, possibilitando ao professor avaliar a criatividade, assim como os avanços do estudante sobre o assunto em estudo constantemente mobilizado para a construção do conhecimento e da realização de suas sínteses, como formas de registro (ANASTASIOU e ALVES, 2005, p. 81-82).

O portfólio que tem o objetivo proporcionar ao professor uma nova forma de avaliação, explorando a capacidade criadora, consiste em uma modalidade de avaliação iniciada no campo das artes, onde se utilizava um compilado de obras, exibindo as habilidades criativas do aluno, combinando profissionalismo, personalidade, paixão e inspiração. Esses portfólios expressavam a capacidade criadora do aluno, por meio dos traços do desenho ou da forma abstrata, como ele via um objeto ou algo que servisse de modelo para a sua criação (GUSMAN, 2002).

O portfólio reflexivo, que se diferencia do introduzido no campo das artes, permite ao aluno registrar e documentar a sua própria aprendizagem por meio de um recurso narrativo, elaborado de forma a ponderar sobre o seu aprendizado e o que seria importante para o seu trabalho como profissional. A narrativa provoca mudança na forma como as pessoas compreendem a si próprias e aos outros. Ao ler seu escrito é possível ao futuro profissional, inclusive, teorizar a própria experiência (MARIN et al., 2010).

Com relação ao estímulo na utilização de portfólios, Cotta et al. (2011, p.416) reforçam:

Do processo de ensino-aprendizagem e de avaliação, destaca-se o portfólio, como instrumento-estratégia de estimulação do pensamento reflexivo. De acordo com Klenowski (2007), o portfólio pode ser definido como um conjunto de trabalhos no qual o estudante retrata sua história de vida, seus progressos e realizações, destacando sua participação na seleção e julgamento dos conteúdos procurados, o que promove uma reflexão e o desenvolvimento da capacidade crítica. Sendo assim, o portfólio apresenta-se como um instrumento capaz de levar o aluno a colecionar suas opiniões, dúvidas, dificuldades, reações aos conteúdos e aos textos estudados e às técnicas de ensino, sentimentos e situações vividas nas relações interpessoais, oferecendo subsídios para a avaliação do estudante, do educador, dos conteúdos e das metodologias de ensino-aprendizagem.

Especificamente sobre a construção do portfólio, Gusman (2002, p. 1) ressalta que:

O Portfólio é um trabalho cuidadosamente tecido pelas mãos dos próprios alunos. Ao fazê-lo, se revelam por meio de diferentes linguagens, pois evidenciam não só que "assimilaram" conteúdos, mas sim como vão se constituindo como profissionais.

Assim, os alunos são descobridores, transformadores e produtores de conhecimento, e a qualidade da produção dos mesmos depende do talento individual. 
Cada aluno possui uma história de vida que pode interferir no processo de ensino. Os alunos possuem inteligências múltiplas, essa teoria foi proposta por Howard Gardner, em 1994, diz que a vida humana requer vários tipos de inteligência, que vai além da linguística e da matemática que a escola oferece. (STREHL, 2000).

Strehl (2000, p. 15), ao falar sobre essas inteligências, destaca que, para o professor:

É fundamental ter uma visão holística dos potenciais envolvidos na consecução eficiente dos conteúdos dos cursos por eles ministrados e, sobretudo, uma compreensão sensível às formas de aprendizado de seus alunos. A adequação dos métodos de ensino aos perfis específicos dos alunos passa a ser fundamental para que as diferenças pessoais - elemento imprescindível para o enriquecimento social e, mais especificamente, do meio profissional - não sejam uma barreira para o aprendizado.

O processo de aprendizagem deve contribuir para o desenvolvimento total da pessoa, espírito, corpo, inteligência, sensibilidade e responsabilidade pessoal. O aluno deve ser preparado, questionado, para elaborar pensamentos autônomos e críticos, formulando seus próprios juízos de valor, tomando decisões diferentes, dependendo da circunstância. A medida que os alunos compreendem esse processo reflexivo, eles conseguem desenvolver uma linguagem crítica aos problemas, buscando soluções (MORAN, 2013).

Conforme Cotta et al. (2012), a mudança na formação se faz necessária e frente a esta realidade e em busca de novos métodos de ensino e de avaliação, que faça com que o aluno desperte para o processo reflexivo e crítico. Ao começar a utilizar o portfólio, por considerar uma ferramenta útil, o professor precisa perceber a construção do aprendizado e, também a partir disso, avaliar os alunos.

Cotta et al. (2011, p.417-418) ressaltam a importância do portfólio no desenvolvimento das competências necessárias ao futuro profissional de saúde: cognitiva, no processo de reflexão, psicológica, tendo consciência do seu papel profissional e mudança na postura de formação, e prática, diretamente relacionada do aluno.

Essa importância assegurada por Cotta et al. (2011) é também encontrada em Villas-Boas (2005, p. 294), quando este destaca: "O portfólio possibilita avaliar a capacidade de pensamento crítico, de articular e solucionar problemas complexos, de trabalhar colaborativamente, de conduحir pesquisa".

Gomes et al. (2010) sugerem o portfólio como um instrumento avaliativo nas atividades desenvolvidas pelos alunos no cenário de práticas, nos serviços e na comunidade, fazendo com que o os alunos sejam um sujeito problematizador, que busca soluções para os problemas enfrentados no dia a dia como profissional. O portfólio, durante a formação, serve para que os alunos registrem suas opiniões e reflexões, o que poderá servir de referência após a conclusão do curso. Gomes et al. (2008) ressaltam que tanto a capacidade reflexiva do aluno e o cumprimento do real papel do portfólio se dará quando o orientador for capacitado para este trabalho, pois este estimulará o aluno na construção de um portfólio realmente reflexivo, que 
contribuirá no seu processo de aprendizagem e que poderá mudar as suas práticas profissionais por meio de um pensamento reflexivo voltado para ação-reflexãoação.

\section{CONTEXTO DA PESQUISA}

Este estudo aborda a utilização do portfólio como uma ferramenta de avaliação e suas potencialidades dentro do processo de ensino e de aprendizagem numa proposta de ensino na formação técnica. Inicia-se a escrita fazendo uma descrição do processo de utilização da ferramenta dentro da sala de aula, após será apresentada a metodologia utilizada e, na sequência, analisados os resultados encontrados nos questionários respondidos pelos sujeitos da pesquisa, tendo como embasamento a análise de conteúdo abordada por Moraes (1999).

\subsection{Portfólio: utilizaçáo da ferramenta em sala de aula}

A importância do instrumento portfólio foi vivenciada durante a formação num curso de educação em saúde. Uma vez experimentada a utilização desta ferramenta na prática, optou-se por aproveitá-la na disciplina de Saúde Coletiva do curso técnico em Enfermagem, do Centro de Educação Profissional (CEP) da Universidade do Vale do Taquari (UNIVATES). Desde o semestre B-2011 os alunos vêm utilizando o portfólio como um instrumento de aprendizagem, compilando todos os trabalhos realizados em sala de aula, incluindo resenhas de textos ou filmes, registrando experiências, recortes de jornais, figuras, imagens, fotos, dentre outros.

Apesar de trabalhar o conceito de portfólio com as turmas e explicar que ele também é um mecanismo de avaliação e que a sua construção se dará no decorrer da disciplina, percebeu-se, com o passar dos anos, a necessidade de elaborar um roteiro de instrução para a elaboração do mesmo, que estará descrito na sequência.

Como supracitado, o portfólio é uma das atividades que faz parte da avaliação da disciplina. Mas, mais do que isso, colabora com a construção do conhecimento do aluno. No início do semestre, apresenta-se a proposta para a turma, explicando que se trata de uma forma diferente de registrar os conteúdos da disciplina que mais impactaram, desenvolver a criatividade e compilar um pouco a história de vida de cada um. Para facilitar a organização do trabalho, o portfólio é subdividido em três etapas, são elas:

- Etapa 1-Abertura: neste momento inicial o aluno relata as suas memórias e o processo de escolha pelo curso técnico em Enfermagem. Trabalhar a sua história, juntamente com os seus objetivos, faz com que o mesmo pense que cada usuário com que ele trabalha também tem um caminho de vida percorrido e traz consigo muitos conceitos e expectativas.

- Etapa 2 - Acadêmica: nesta fase o aluno deverá apresentar um relato sobre as discussões realizadas em sala de aula, de acordo com os temas propostos no cronograma. Fazendo uma análise crítica reflexiva sobre as políticas de saúde 
apresentadas e construindo o conceito ampliado de saúde, aprendendo a trabalhar em equipe. O portfólio é um documento dinâmico, ficando a critério da criatividade do estudante a sua forma de construção.

- Etapa 3 - Finalização: a parte final consiste em ajudá-lo a refletir sobre a prática do técnico em Enfermagem na saúde coletiva, confrontando com os conhecimentos apreendidos durante a disciplina.

A entrega do portfólio se dá em dois momentos: a etapa inicial, referente a história de vida, ocorre na quinta aula, e o restante, na penúltima aula. A Figura 1 ilustra algumas capas de trabalhos construídos pelos alunos.

Figura 1 - Exemplificações de portfólios construídos pelos alunos
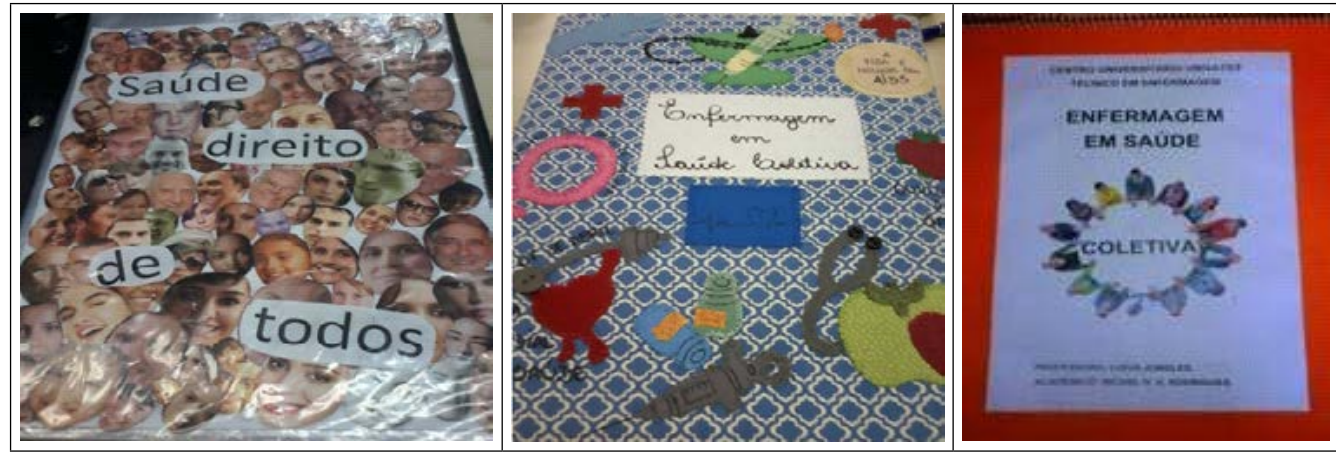

Fonte: Da autora (2017).

Após a entrega da versão final do portfólio da disciplina de Saúde Coletiva, é realizada a leitura e a avaliação do mesmo, atentando para as orientações combinadas no início do semestre. Por fim, é agendado um encontro a dois, entre professora e estudante, onde se discutem alguns pontos relacionados ao portfólio e, somente depois, finaliza-se o processo.

\section{METODOLOGIA DA PESQUISA: construindo possibilidades}

Este estudo foi do tipo exploratório descritivo, com abordagem qualitativa, que propôs investigar uma prática pedagógica desenvolvida em sala de aula, partindo da utilização do portfólio. Seguiu com a elaboração de um questionário, composto por dez questões, que foi distribuído aos alunos da turma, para que o respondessem em casa. Após a devolutiva deste questionário, cada respondente foi identificado pela letra A (de Aluno) associada a um número. As respostas foram analisadas qualitativamente, observando e categorizando o conteúdo das mesmas.

A abordagem qualitativa, segundo Moraes (2003, p. 191):

[...] é realizado uma análise textual, partindo de textos já existentes, seja produzindo o material de análise a partir de entrevistas e observações, a pesquisa qualitativa pretende aprofundar a compreensão dos fenômenos que investiga a partir de uma análise rigorosa e criteriosa desse tipo de informação, 
isto é, não pretende testar hipóteses para comprová-las ou refutá-las ao final da pesquisa; a intenção é a compreensão.

Neste estágio do trabalho foi verificado o teor das respostas dissertativas dos alunos ao questionário e realizada a análise de conteúdo, que se deu, resumidamente, da seguinte forma: a partir da transcrição fiel de todas as respostas dos questionários, com as autorias identificadas como A1, A2, A3, etc. Foi realizada a leitura e releitura do material coletado e, de acordo com o conteúdo do texto, elaboradas as categorias que, por fim, serviriam para posterior análise e interpretação da pesquisa. Todo este processo está respaldado em Moraes (1999, p. 4), que trabalha a análise de conteúdo por meio de cinco etapas, são elas: preparação, unitarização, categorização ou classificação das unidades em categorias, descrição e interpretação.

Para Moraes (1999), a preparação dos dados se divide em dois momentos, onde são realizadas a identificação das amostras e a codificação das mesmas. Este foi o processo utilizado nesta pesquisa, na qual os alunos foram identificados por diferentes números. A unitarização é descrita pelo mesmo autor como um processo de leitura cuidadosa, para posterior identificação de unidade de análise e definição da harmonia de contexto de cada uma. Já na categorização é necessário agrupar dados, por isso, mais uma vez, Moraes (1999) sugere uma releitura com observação das partes comuns entre os elementos presentes na escrita. Neste momento, na pesquisa aqui relatada foram analisadas todas as respostas do questionário e identificadas palavras ou frases comuns entre os respondentes, o que se constituiu nas categorias que serviram de aporte para esta investigação.

Na etapa da descrição, o autor destaca que, após a identificação das categorias, é realizada a análise dos aspectos comuns desencadeando numa visão detalhada do processo. Neste sentido, nesta pesquisa foram identificadas sete categorias, que foram descritas com informações pertinentes a cada uma delas, a partir da descrição do conteúdo encontrado nas respostas. Por fim, como última etapa do processo, Moraes (1999) destaca que a análise do conteúdo não deve se basear apenas na descrição e, sim, interpretar os dados apresentados, o que também ocorreu nesta pesquisa.

\section{ANÁLISE DOS RESULTADOS:}

Durante o semestre A-2017, visando agregar potencialidades à ferramenta portfólio, foi realizado um questionário para avaliar esta estratégia de ensino. Conforme já citado anteriormente, esta atividade foi realizada com uma turma da disciplina de Saúde Coletiva, do curso técnico em Enfermagem, do Centro de Educação Profissional da UNIVATES, localizado em Lajeado/RS. Solicitou-se que a turma, inicialmente constituída por 40 alunos, mas, no final do semestre, com 37 concluintes, respondesse em casa a um questionário com dez perguntas (FIGURA 2). No total, foram distribuídos 37 questionários, dos quais retornaram 31, o que representa $83,78 \%$ de respondentes. 
Figura 2 - Questionário investigativo da ferramenta portfólio

Centro de Educação Profissional (CEP) - UNIVATES
Questionário da pesquisa
1) Descreva o processo de construção do porttólio?
2) O portfólio contribuiu para o seu processo de aprendizagem? Justifique.
3) As informações contidas no seu porttólio são relevantes para ações futuras dentro da
profissão de um Técnico em Enfermagem? Justifique.
4) Você utilizaria o porttólio para consulta durante o estágio em Saúde Coletiva?
Justifique.
5) Você considera importante o registro de outras disciplinas na elaboração do portfólio,
para que o mesmo fosse utilizado como meio de consulta durante o periodo de estágio?
Explique.
6) O portfólio contribuiu para a sua formação acadêmica e o desenvolvimento da sua
capacidade crítica reflexiva? Por quê?
7) Em escala de 1 à 10, avalie a importância da construção do porttólio?Justifique.
8) Em escala de 1 à 10, avalie o aspecto final porttólio?Justifique.
9) Quais as maiores dificuldades na construção do porttólio?
10) Observações.

Fonte: Da autora (2017).

Com relação ao questionário, foram averiguados os resultados em conformidade com a metodologia inicialmente proposta. Neste sentido, optou-se por iniciar pela análise quantitativa e, por isso, serão apresentadas as questões 7 e 8 .

$\mathrm{Na}$ avaliação da importância do portfólio, questão número 7 do questionário, considerando uma escala de 1 a 10, prevaleceram respostas no intervalo entre 8 e 10, conforme distribuição no Quadro 1. 
Quadro 1 - Avaliação da importância do portfólio

\begin{tabular}{|c|c|}
\hline Nota de importância do portfólio & Percentual de respondentes \\
\hline 8 & $23,3 \%$ \\
\hline 9 & $30 \%$ \\
\hline 10 & $46,7 \%$ \\
\hline
\end{tabular}

Fonte: Da autora (2017).

Já no que se refere ao aspecto final do portfólio, questão número 8 do questionário, também utilizando uma escala de 1 a 10 , os alunos respondentes avaliaram entre 6 e 10, seguindo a distribuição do Quadro 2.

Quadro 2 - Avaliação da importância do portfólio

\begin{tabular}{|c|c|}
\hline Aspecto final portfólio & Percentual de respondentes \\
\hline 6 & $6,5 \%$ \\
\hline 7 & $22,6 \%$ \\
\hline 8 & $25,7 \%$ \\
\hline 9 & $22,6 \%$ \\
\hline 10 & $22,6 \%$ \\
\hline
\end{tabular}

Fonte: Da autora (2017).

Realizando um comparativo entre as questões 7 e 8 , pode-se perceber que a maioria dos respondentes considera o portfólio como uma ferramenta importante. Mas, quando solicitada uma nota para o seu portfólio, a maioria respondeu que ela seria 8 , justificando tal valor na dificuldade de construção do instrumento pela falta de tempo e o excesso de trabalhos, também desenvolvidos em outras disciplinas A 15 "Poderia ter me dedicado mais, se tivesse tempo e não tivesse tantos trabalhos das outras disciplinas".

Para as questões números 1 até 6 e também a número 9, utilizou-se a análise de conteúdo embasada em Moraes (1999). Deste diagnóstico emergiram sete categorias, são elas: materiais e métodos utilizados em sala de aula para o processo de construção do portfólio, história de vida e a escolha pelo curso técnico em Enfermagem, processo de aprendizagem, utilização do portfólio como consulta durante o estágio e na vida profissional, construção de um portfólio interdisciplinar, desenvolvimento da capacidade crítica reflexiva durante a formação e dificuldades enfrentadas no processo de construção do portfólio. Em todas as categorias podese perceber a potencialidade da ferramenta portfólio. 


\subsection{Categoria 1: Materiais e métodos utilizados em sala de aula para o processo de construçáo do portfólio}

Para realizar a construção do portfólio, os alunos acabaram utilizando materiais disponíveis em sala de aula. Um total de 29 estudantes relatou utilizar caderno, anotações e conteúdos abordados em aula. Além disso, 14 envolvidos relataram buscar suporte na internet, em imagens, em leituras e outras fontes, que pudessem aprimorar o conhecimento e que ajudasse na criação do instrumento. Apesar de todos os relatos serem positivos e citarem os materiais disponíveis no ambiente virtual e distribuídos em aula, alguns alunos encontraram dificuldades no registro e no processo de construção, sendo que esta constatação foi apontada por 4 indivíduos. Marin et al. (2010) destacam que este processo de construção pode causar apreensão, insegurança e rejeição ao seu uso. A 20 "O que é portfólio por onde eu começo...nunca fiz isso". No início do semestre, no momento da apresentação da tarefa, percebeu-se a presença dos aspectos citados pelo autor e, por isso, foi elaborado um roteiro de construção para facilitar o processo e tranquilizar a turma.

\subsection{Categoria 2: História de vida e a escolha pelo curso técnico em Enfermagem}

Todos os alunos, durante o processo de construção do portfólio, escreveram sobre a sua história de vida e o porquê da escolha pelo curso técnico em Enfermagem. Mas, na hora de responder ao questionário, apenas 14 citaram essa etapa do processo. Trabalhar a história de vida com os alunos fez com que os mesmos refletissem sobre o processo de cuidado, pois todos têm uma história e conceitos que trazem consigo para o atendimento. Foi perceptível que, em todos os portfólios, a escolha pela profissão estava relacionada a sua história de vida. Valore (2008) relata que a definição profissional se dá mediante as relações que se constroem ao longo da vida, mediante os vínculos com outras pessoas, conosco e com o mundo. Vale apontar que emergiu das manifestações dos alunos que o falar e o escrever sobre a sua história de vida não é tarefa fácil. Tal constatação pode ser exemplificada na fala do aluno identificado como A31: "Nessa etapa do portfólio tive um pouco de dificuldade [] Não é fácil falar de mim ou escrever sobre mim. Mas fiz o solicitado para contemplar essa etapa”.

\subsection{Categoria 3: Processo de aprendizagem}

No que se refere ao processo de aprendizagem, 100\% dos alunos disseram que o portfólio contribui no processo, pois eles conseguem rever o conteúdo abordado em sala de aula e buscam aprofundar o mesmo com pesquisa na internet. Neste aspecto, cabe ressaltar a citação do aluno A30: "O processo de construção do conhecimento se dá de forma gradativa durante o semestre, à medida que íamos discutindo o conteúdo e pesquisando". O portfólio, no processo de ensino e aprendizagem, se torna uma excelente ferramenta na construção do conhecimento, 
pois permite ao aluno criar com autonomia e vivenciar experiências que vão além da questão avaliativa (VIVEIROS; MARQUES, 2017). Assim, o instrumento tem potencial para qualificar o ensino-aprendizagem, porém ainda é pouco usado no campo educacional, pois é difícil definir o protagonismo do aluno neste processo (REZENDE, 2010).

O portfólio é uma ferramenta cuja a construção é livre, o que dá liberdade e autonomia para o aluno criar, recriar e repensar muitas vezes a sua prática de trabalho. Ao participar desta proposta, ele desenvolve a habilidade de pesquisa, de sintetizar e de interpretar os assuntos trabalhados. Na vida profissional, o egresso terá que utilizar todas estas habilidades no campo técnico. Isso corrobora com Rezende (2010) que destacam a visão emancipatória do sujeito ao vivenciar novas experiências. Consegue-se perceber na construção do portfólio a individualidade de cada um dos alunos, as suas dificuldades e as suas percepções. Quando Rezende (2010) relata sobre a pouca utilização da ferramenta pelos docentes, poderia ser acrescentada como ponto dificultador a forma de avaliação.

Como avaliar esta construção, este protagonismo? O processo avaliativo do portfólio proposto nesta escrita limita-se a avaliar se o aluno contemplou ou não todas as etapas do processo de construção, tendo como peso maior a etapa acadêmica, onde é possível perceber se os conceitos estudados e discutidos foram, de fato, assimilados. Por fim, o agendamento de um encontro a dois, professor e aluno, onde há uma devolutiva desta avaliação individualmente, também é fator a ser destacado.

\subsection{Categoria 4: Utilização do portfólio como consulta durante o estágio e na vida profissional}

Com relação a esta categoria, novamente $100 \%$ dos alunos disseram que utilizariam o portfólio como meio de pesquisa durante a sua vida profissional e acadêmica, pois o mesmo continha informações e conteúdos relevantes, como por exemplo: folders, imagens, entre outros, que facilita o processo de pesquisa. Cotta et al. (2012) ressaltam a importância do portfólio como instrumento problematizador das práticas, pois os alunos aprendem a conhecer e são capazes de avaliar criticamente o sistema de saúde, possibilitando, também, uma visão ampliada da saúde e seus determinantes. Neste sentido e com relação ao portfólio no sentido profissional, Cotta et al. (2012, p.417) destacam ainda:

Desenvolvimento de competências necessárias ao futuro profissional de
saúde: cognitiva (reflexão), psicológica (consciência do seu papel profissional)
e atitudinal (mudança de postura na formação e prática do aluno baseado nas
DCN e na consolidação do SUS)..

$\mathrm{Na}$ fala do aluno A25: “Todas as informações contidas no portfólio são relevantes, estão voltadas a teoria e práticas de abordagem, não só no estágio, mas na prática profissional". "A15: Tudo o que tem no portfólio eu posso usar no futuro, como profissional”. Ou seja, a percepção dos envolvidos está em conformidade com os estudos apresentados. 


\title{
5.5 Categoria 5: Construção de um portfólio interdisciplinar
}

A construção de um portfólio interdisciplinar, onde constam outras disciplinas e conteúdos que possam facilitar a consulta durante a vida profissional e acadêmica, foi lembrada por $91 \%$ dos alunos respondentes, que disseram ser importante. Apenas $9 \%$ alegaram não ser necessário. Destes $9 \%$, um não justificou sua resposta negativa, um argumentou que tem matérias que não se usa no estágio e, por isso, não precisaria de um portfólio interdisciplinar e um fundamentou que cada disciplina é uma disciplina e possui os seus próprios métodos de ensino.

A importância da interdisciplinaridade foi verificada em muitas manifestações, como na fala do aluno A31, que relata: "A área da enfermagem é muito abrangente precisamos ser profissionais pesquisadores o portfólio só tem a agregar conhecimento facilitando o ensino e agregando conhecimento deveria ser uma das atividades desenvolvidas nas demais disciplinas do curso".

\begin{abstract}
A interdisciplinaridade permite-nos esperar a produção de um conhecimento científico novo a partir de duas ou mais diferentes áreas de conhecimento que se integram. A interdisciplinaridade pode se manifestar pelo diálogo e troca de conhecimentos, de análises, de métodos entre duas ou mais disciplinas e pela transferência de métodos de uma disciplina para outra na resolução de um problema. Trata-se de outra forma de produção de conhecimento, de articulação de saberes. (MASSETO, 2011)
\end{abstract}

\subsection{Categoria 6: Desenvolvimento da capacidade crítica reflexiva durante a formaçáo}

Todos respondentes afirmaram que o portfólio ajudou no desenvolvimento da capacidade crítica reflexiva durante a formação como técnico em Enfermagem. Os aspectos enfatizados nesta abordagem apontavam que o portfólio ajuda a compreender, a refletir, a entender o cuidado, o atendimento mais humanizado e a capacidade de resolver situações do dia a dia do profissional. Assim, é possível vislumbrar que este instrumento é um método eficaz no processo de ensino e de aprendizagem, fazendo com que os alunos reflitam sobre a sua prática e construam pelas suas mãos algo que pode ser utilizado no estágio e na vida profissional. A 10 "O portfólio fez com eu repensasse os conteúdos abordados e pensasse na minha prática. Vou poder utilizar ele no meu estágio”. A formação profissional implicasse em entender a aprendizagem como um processo contínuo, alicerçados na busca de novas ideias e valores. O portfólio traz um pouco desse recordatório da formação efetivada durante o curso. (COTTA, 2012)

\subsection{Categoria 7: Dificuldades enfrentadas no processo de construçáo do portfólio}

No processo de construção do portfólio, $50 \%$ dos alunos respondentes relataram que tiveram alguma dificuldade. O principal apontamento foi selecionar o que seria importante para eles naquele momento, para ir construindo o portfólio, 
a sua capacidade de síntese nos registros realizados. Outro ponto destacado foi o tempo para desenvolver a atividade e a criatividade na elaboração do produto final. O aluno A19 destaca: "Encontrar as partes mais importantes, pois tudo que foi visto era importante para o estágio. Mas coloquei parte do que eu achei importante".

O portfólio é uma ferramenta avaliativa diferente daquelas que os alunos estão acostumados. $\mathrm{Na}$ elaboração do instrumento é possível desenvolver algumas habilidades específicas, como a de refletir sobre a sua prática, solucionar problemas do dia a dia e a capacidade de sintetizar as informações necessárias para o trabalho. Quando são apresentadas novas propostas avaliativas, diferente da memorização, é comum perceber um pouco de resistência por parte dos envolvidos, sejam alunos ou professores. $\mathrm{Na}$ educação profissional ainda existe outra dificuldade: o tempo disponível, pois a maioria dos alunos do ensino técnico trabalha e estuda, então o tempo se torna um limitador e é necessário encontrar uma nova forma para aprender.

\section{CONSIDERAÇÓES FINAIS}

Com as novas Diretrizes Curriculares, que propõem mudanças na formação, a utilização de metodologias de ensino inovadoras e avaliação diferenciada se fazem necessárias. Para que isso ocorra é preciso atualizar os docentes no uso dessas novas estratégias pedagógicas e preparar os alunos para essa mudança no ensino.

Este estudo permitiu identificar que o portfólio é uma das ferramentas que pode ser utilizada como método de avaliação e construção do conhecimento. Todas as manifestações dos questionários relataram a importância do instrumento, permitindo vislumbrar-lo como um instrumento pedagógico muito eficaz.

O portfólio, no estudo de caso apresentado, se tornou uma coletânea de informações e trabalhos, que os alunos consideraram importante para utilização no estágio e na vida profissional. Neste sentido, contribuiu para o desenvolvimento da capacidade crítica reflexiva dos envolvidos. O que corrobora com Costa e Cotta (2014), quando afirmam que o portfólio é uma ferramenta inovadora, que permite a autonomia da aprendizagem, desenvolvendo no aluno a capacidade crítica reflexiva e a habilidade de criar e buscar soluções para os problemas, além de estimular elementos de uma formação para o ser.

Ademais, o portfólio é uma ferramenta que poderia ser utilizada interdisciplinarmente dentro do curso, formando um compilado de aprendizagem e informações a ser usado futuramente pelos estudantes. Para que isso ocorra, é preciso orientar os professores, incentivando-os a utilizarem a ferramenta e discutindo com os mesmos a melhor forma a ser utilizada e avaliada. Costa e Cotta (2014, p.781) destacam a importância do portfólio como método inovador no processo de avaliação. Existem evidências que subsidiam a necessidade de mudanças, mas para que isso ocorra se faz necessária a reformulação dos currículos, buscando que os mesmos sejam mais integrados e que os professores estejam capacitados para o uso de novos métodos, repensando a forma de ensinar e também de avaliar. Portanto, é indispensável discutir e reformular os programas de ensino dentro dos cursos 
de educação profissional, para que os mesmos possam se adequar às Diretrizes Curriculares Nacionais (BRASIL, 2001; 2012).

Por fim, é preciso destacar as importantes manifestações recolhidas no questionário respondido pelos alunos. Reforçando na prática a teoria de que o portfólio é uma ferramenta muito importante, que desenvolve no estudante a habilidade crítico reflexiva, tornando-o o centro do seu aprendizado e estimulando a capacidade de realizar releituras sobre os temas debatidos a partir da sua própria opinião. Enfim, o portfólio pode apresentar várias possibilidades, mas tem como principal fator a construção do conhecimento pelo aluno.

\section{REFERÊNCIAS}

ANASTASIOU, L. das G. C. ALVES, L. P. Processos de ensinagem na universidade pressupostos para as estratégias de trabalho em aula. 5. ed. - Joinville/SC: UNIVILLE, 2009. Cap. 3.

BEHRENS, M. A. O paradigma emergente e a prática pedagógica. Petrópolis: Vozes; 2005.

BRASIL. Ministério da Educação. Conselho Nacional de Educação. Parecer CNE/CES 1133/2001. Diário Oficial da União, 03/10/2001. Brasilia, Distrito Federal. Disponível em: <portal.mec.gov.br/dmdocuments/ces1133.pdf>. Acesso em: 22 jun. 2017.

. Ministério da Educação. Conselho Nacional de Educação. Câmara de Educação

Superior. Resolução CNE/ CES n. 3. 07/11/2001. Diário Oficial da República Federativa do Brasil. Brasília (DF), 9 nov. 2001. Seção 1, p.37.

. Ministério da Educação. Conselho Nacional de Educação. Câmara da Educação Básica. Resolução no 6. 20/09/2012. Disponível em: < portal.mec.gov.br/index. php?option $=$ com_content\&view $=$ article\&id $=17417 \&$ Itemid $=86>$. Acesso em: 23 jun. 2017.

CIAVATTA, M. A formação integrada: a escolar e o trabalho como lugares de memória e de identidade. In: FRIGOTTO, G.; CIAVATTA, M.; RAMOS, M. (Org.). Ensino Médio Integrado: Concepção e Contradições. 3. ed. São Paulo: Cortez, 2012. p.83-107.

COSTA, G. D.; COTTA, R. M. M. El aprender haciendo: representaciones sociales de estudiantes de la salud del portafólio reflexivo como método de enseñanza, aprendizaje y evaluación. Interface (Botucatu) [online]. 2014, vol.18, n.51, pp.771-784. Epub Sep 26, 2014. Disponível em: <dx.doi.org/10.1590/1807-57622014.0150>. Acesso em: 23 ago. 2017.

COTTA, R. M. M.; MENDOCA , É.T. ; COSTA, G, D., . Portfólios reflexivos: construindo competências para o trabalho no Sistema Único de Saúde. Rev. Panam. Salud. Pública. 2011. Disponível em: < www.scielosp.org/pdf/rpsp/v30n5/v30n5a03> Acesso em: 02 maio 2017. 
Cotta, R. M. M., Silva, L. S. D., Lopes, L. L., Gomes, K. D. O., Cotta, F. M., Lugarinho, R., \& Mitre, S. M. Construção de portfólios coletivos em currículos tradicionais: uma proposta inovadora de ensino-aprendizagem. Ciência \& Saúde Coletiva, v. 17, n. 3 , 2012. Disponível em: </http://www.redalyc.org/html/630/63023334028>. Acesso em: 02 maio 2017.

CYRINO, E. G.; TORALLES-PEREIRA, M. L. Trabalhando com estratégias de ensino-aprendizado por descoberta na área da saúde: a problematização e a aprendizagem baseada em problemas. Cadernos de saúde pública. Ministério da Saúde. Fundação Oswaldo Cruz. Escola Nacional de Saúde Pública, p. 780-788, 2004. Disponível em: <n/www.scielo.br/pdf/csp/v20n3/15>. Acesso em: 15 jul. 2017.

GARDNER, H. Estruturas da mente: a Teoria das Múltiplas Inteligências. Porto Alegre: Artes Médicas, 1994.

\section{GASTARDELLI, G. Metodologias Ativas - Desafios para uma Educação} Disruptiva. Porto Alegre, 2016.

Gomes, A. P., Dias-Coelho, U. C., Cavalheiro, P. D. O., Gonçalvez, C. A. N., Rôças, G., \& Siqueira-Batista, R. . A educação médica entre mapas e âncoras: a aprendizagem significativa de David Ausubel, em busca da arca perdida. Rev. Bras. Educ. Méd. V.32, n.1, p.105-111, 2008. Disponível em: <bb99fwww.researchgate.net/profile/ Giselle_Rocas/publication/250991681_A_Educacao_Medica_entre_mapas_e_ ancoras_a_aprendizagem_significativa_de_David_Ausubel_em_busca_da_Arca_Perdida/ links/564b0b6608ae9cd9c827f3ed.pdf>. Acesso em: 22 jun. 2017.

Gomes, A. P., Arcuri, M. B., Cristel, E. C., Ribeiro, R. M., Souza, L. M. B. M., \& SiqueiraBatista, R. Avaliação no ensino médico: o papel do portfólio nos currículos baseados em metodologias ativas. Rev Bras Educ Med, v. 34, n. 3, p. 390-6, 2010.

Disponível em: <ltc-ead.nutes.ufrj.br/constructore/objetos/Avalia $\%$ e $7 \%$ e $30 \% 20$ no $\% 20$ Ensino $\% 20 \mathrm{M} \%$ e9dico $\% 20$ o $\% 20$ papel $\% 20$ do $\% 20$ portf $\%$ f3lio $\% 20$ nos $\% 20$ curr $\%$ edculos $\% 20$ baseados $\% 20 \mathrm{em} \% 20$ metodologias $\% 20$ ativas.pdf $>$. Acesso em: 22 jun. 2017.

Gusman, A. B., de Rezende, E. M. M., Loyola, M. E. S., de Abreu, N., Hinkle, A. R., Pucci, B. R. F., ... \& Maxwell, L. J. PORTFÓLIO: conceito e construção. Uberaba: Instituto de Formação de Educadores. Universidade de Uberaba, 2002. Disponível em: $<$ www.uniube.br/biblioteca/novo/udi/rondon/arquivos/portfolio_biblioteca_uniube. pdf $>$. www.uniube.br/biblioteca/novo/udi/rondon/arquivos/portfolio_biblioteca_ uniube.pdf>. Acesso em: 02 maio 2017.

MARIN, M. J. S. et al. O uso do portfólio reflexivo no curso de medicina: percepção dos estudantes. Rev. Bras. Educ. Med. V.34, n.2, p.191-8, 2010. Disponível em: <nvnwww.scielo.br/pdf/rbem/v34n2/a02v34n2>. Acesso em: 02 jun. 2017.

MASETTO, Marcos Tarciso. Inovação na aula universitária: espaço de pesquisa, construção de conhecimento interdisciplinar, espaço de aprendizagem 
e tecnologias de comunicação - doi: 10.5007/2175-795X.2011v29n2p597.

Perspectiva, Florianópolis, v. 29, n. 2, p. 597-620, jun. 2011. ISSN 2175-795X.

Disponível em: < https://periodicos.ufsc.br/index.php/perspectiva/article/

view/2175-795X.2011v29n2p597/22219>. Acesso em: 26 jun. 2018. doi:https://doi. org/10.5007/2175-795X.2011v29n2p597.

MORAN, J. M. Novas tecnologias e mediação pedagógica. $21^{\mathrm{a}}$ ed. rev. e atual. Campinas, SP: Papirus, 2013.

MORAES, R. Análise de conteúdo. Revista Educação, Porto Alegre. V.22, n.37, p.7-32, 1999. Disponível em: <cliente.argo.com.br/ mgos/analise_de_conteudo_moraes.html>. Acesso em: 02 jul. 2017.

. Uma tempestade de luz: a compreensão possibilitada pela análise textual discursiva. Ciência \& Educação. V.9, n.2, p.191-211, 2003. Disponível em: <92www. scielo.br/pdf/ciedu/v9n2/04>. Acesso em: 15 jul. 2017.

MOURA, D. H. Mudanças na sociedade brasileira dos anos 2000 limitadas pela hegemonia do neoliberalismo: implicações para o trabalho e para a educação. In: Produção de Conhecimento, Políticas Públicas e Formação Docente em Educação Profissional. Campinas: Mercado de Letras, 2013. p.109-141.

Paiva, M. R. F., Parente, J. R. F., Brandão, I. R., \& Queiroz, A. H. B. Metodologias ativas de ensino-aprendizagem: revisão integrativa. SANARE - Revista de Políticas Públicas. V.15, n.2, 2017. Disponível em: <sanare.emnuvens.com.br/sanare/article/ view/1049>. Acesso em: 22 ag. 2017.

RAMOS, M. Concepção do ensino médio integrado. 2015. Texto digital. Disponível em: <tecnicadmiwj.files.wordpress.com/2008/09/texto-concepcao-do-ensino-mediointegrado-marise-ramos1.pdf>. Acesso em: 08 ag. 2017.

RAMOS, A. Metodologia da pesquisa científica: como uma monografia pode abrir o horizonte do conhecimento. São Paulo: Atlas, 2009.

REZENDE, M. A. R. A relação pedagógica e a avaliação no espelho do portfólio: memórias docentes e discentes. 2010. 279 f. Tese (doutorado em Educação).

Faculdade de Educação, Universidade Federal de Minas Gerais, Belo Horizonte, 2010. Disponível em: <http://hdl.handle.net/1843/FAEC-87YPQC>. Acesso em: 22 ag. 2017.

Santos, M. G., Morais, J. K. C., \& Brandão, P. A.. O caminho dos professores na educação profissional: percepções sobre o sentido do trabalho e do trabalho docente. Revista Brasileira da Educação Profissional e Tecnológica. V.1, n.12, p.96-110, 2017. Disponível em: <2www2.ifrn.edu.br/ojs/index.php/RBEPT/article/view/5717>. Acesso em: 16 set. 2017.

STREHL, L. Teoria das Múltiplas Inteligências de Howard Gardner: breve resenha e reflexões críticas. Trabalho apresentado com requisito parcial para a conclusão da 
disciplina Seminário sobre Ensino de Comunicação e Informação, 2000. Disponível em: <chasqueweb.ufrgs.br/ leticiastrehl/HowardGardner.pdf>. Acesso em: 16 set. 2017.

VALORE, L. A. A problemática da escolha profissional: a possibilidades e compromissos da ação psicológica. SILVEIRA, A. F., et al. (org.). Cidadania e participação social [online]. Rio de Janeiro: Centro Edelstein de Pesquisas Sociais, 2008. pp.66-76. Disponível em: <static.scielo.org/scielobooks/hn3q6/pdf/ silveira-9788599662885.pdf\#page=72>. Acesso em: 22 ag. 2017.

VILLAS-BOAS, B. M. F. O portfólio no curso de pedagogia: ampliando o diálogo entre professor e aluno. Educ. Soc. 2005; Disponível em: <0nvwww.scielo.br/ pdf/\%0D/es/v26n90/a13v2690.pdf>. Acesso em: 12 jul. 2017.

VIVEIROS, A.; MARQUES, R. de C. Uso do portfólio como ferramenta avaliativa em uma disciplina do curso de Nutrição da Universidade Federal de Minas

Gerais. Revista Docência do Ensino Superior 7.1 (2017). Disponível em: <seer.lcc.ufmg. br/index.php/rdes/article/view/1960>. Acesso em: 22 ag. 2017.

WILDNER, M. C. S. Metodologias Ativas de Ensino e Aprendizagem. Notas de aula. Pós-graduação. Lajeado. 2016. 